\title{
Metaplastic effect of apamin on LTP and paired-pulse facilitation
}

\author{
Laurence Ris, ${ }^{1}$ Brigitte Capron, ${ }^{1,2}$ Coralie Sclavons, ${ }^{1}$ Jean-François Liégeois, ${ }^{3}$ \\ Vincent Seutin, ${ }^{4}$ and Emile Godaux ${ }^{1,5}$ \\ ${ }^{1}$ Laboratory of Neurosciences, University of Mons-Hainaut, 7000 Mons, Belgium; ${ }^{2}$ Department of Neurology, UCL, 1000 Brussels, \\ Belgium; ' Laboratory of Medicinal Chemistry, University of Liège, 4000 Liège, Belgium; ${ }^{4}$ Laboratory of Pharmacology and Center \\ for Cellular and Molecular Neurobiology, University of Liège, 4000 Liège, Belgium
}

\begin{abstract}
In area CAl of hippocampal slices, a single $1-$ sec train of $100-\mathrm{Hz}$ stimulation generally triggers a short-lasting long-term potentiation (S-LTP) of 1-2 h. Here, we found that when such a train was applied 45 min after application of the small conductance $\mathrm{Ca}^{2+}$-activated $\mathrm{K}^{+}$(SK) channel blocker apamin, it induced a long-lasting LTP (L-LTP) of several hours, instead of an S-LTP. Apamin-induced SK channel blockage is known to resist washing. Nevertheless, the aforementioned effect is not a mere delayed effect; it is metaplastic. Indeed, when a single train was delivered to the Schaffer's collaterals during apamin application, it induced an S-LTP, like in the control situation. At the moment of this LTP induction (15th min of apamin application), the SK channel blockage was nevertheless complete. Indeed, at that time, under the influence of apamin, the amplitude of the series of field excitatory postsynaptic potentials (fEPSPs) triggered by a stimulation train was increased. We found that the metaplastic effect of apamin on LTP was crucially dependent on the NO-synthase pathway, whereas the efficacy of the NMDA receptors was not modified at the time of its occurrence. We also found that apamin produced an increase in paired-pulse facilitation not during, but after, the application of the drug. Finally, we found that the induction of each of these two metaplastic phenomena was mediated by NMDA receptors. A speculative unitary hypothesis to explain these phenomena is proposed.
\end{abstract}

Synaptic plasticity is believed to be at the basis of learning and memory (Kandel 2001). Long-term potentiation (LTP) of synaptic transmission induced in area CA1 of hippocampal slices by delivering one or multiple trains of high-frequency stimulation (HFS) to the Schaffer collaterals is one of the most studied models of synaptic plasticity. After slicing, slices must be left undisturbed for $\sim 1 \mathrm{~h} 30 \mathrm{~min}$ (recovery period) before starting the recordings (recording period). When both recovery and recordings occur in interface, a single 1 -sec train at $100 \mathrm{~Hz}$ induces a short-lasting LTP (S-LTP) of 1-2 h, whereas multiple 1-sec trains induce a longlasting LTP (L-LTP) of several hours (Huang and Kandel 1994; Abel et al. 1997; Kelleher et al. 2004). In a recent study, we found that allowing the slices to recover "in submersion" had dramatic metaplastic effects. In these conditions, a single 1 -sec train at 100 $\mathrm{Hz}$ induced an L-LTP instead of an S-LTP (Capron et al. 2006). This result motivated us to search for a pharmacological agent that, when applied during the recovery in interface, would duplicate the dramatic effect of "recovery in submersion" on the duration of LTP. We found that the bee-venom toxin apamin, a blocker of the small conductance $\mathrm{Ca}^{2+}$-activated $\mathrm{K}^{+}(\mathrm{SK})$ channel, produced such an effect.

SK channels are molecular complexes of four pore-forming subunits with four constitutively associated calmodulin (CaM) molecules (Xia et al. 1998; Keen et al. 1999). It has been repeatedly claimed that SK channels mediated the medium afterhyperpolarization (mAHP, typically lasting $50-200 \mathrm{msec}$ ) in hippocampal CA1 neurons (Sah 1996; Stocker et al. 1999; Bond et al. 2004). However, a recent extensive study has shown that SK channels made little or no net contribution to the mAHP of CA1 pyramidal neurons, found to be dependent on $\mathrm{M}$ and $\mathrm{h}$ channels ( $\mathrm{Gu}$ et al. 2005). Because their activation causes hyperpolarization, SK

\footnotetext{
${ }^{5}$ Corresponding author.
}

E-mail emile.godaux@umh.ac.be; fax 32-65-373573.

Article is online at http://www.learnmem.org/cgi/doi/10.1101//m.571007. channels likely play an important role in the regulation of neuronal excitability (Stocker et al. 1999). Four SK channel family members have been cloned, and three of them are expressed in the CNS: SK1, SK2, and SK3 (Köhler et al. 1996; Joiner et al. 1997; Stocker and Pedarzani 2000). SK2 and SK3 are blocked by apamin, whereas SK1 is apamin-insensitive (Köhler et al. 1996). In contrast to SK1 and SK2, which are strongly expressed in the pyramidal and granule cell layer throughout the hippocampus, SK3 is preferentially expressed in CA3 and the dentate gyrus (Stocker and Pedarzani 2000). Interestingly, it has recently been demonstrated that NMDA receptors (NMDARs), which are crucial for synaptic plasticity, and SK2 channels are colocalized in the dendritic spines of CA1 pyramidal neurons (Ngo-Anh et al. 2005). In contrast, SK3 channels have been found to be located on the presynaptic terminals of cultured hippocampal pyramidal neurons (Obermair et al. 2003).

Improvement of learning and memory through apamin treatment in vivo has been reported repeatedly (Messier et al. 1991; Deschaux et al. 1997; Fournier et al. 2001), whereas agerelated memory deficit has recently been ascribed to a heightened expression of SK3 in the brain of aged animals (Blank et al. 2003). Apamin has also been reported to influence the LTP induced in the CA1 region of hippocampal slices when present at the moment of induction (Behnisch and Reymann 1998; Stackman et al. 2002; Kramár et al. 2004). Here, we describe not an immediate, but a delayed, metaplastic effect of apamin on LTP.

\section{Results}

Delayed facilitation of L-LTP induction by apamin applied during the recovery period

In all the experiments carried out here, the slices were left undisturbed after slicing for $1.5 \mathrm{~h}$ (recovery period) before starting to collect the data (recording period). An interface chamber was used for both recovery and recording. When the experiments 
were performed in artificial cerebrospinal fluid (aCSF) containing $\mathrm{Mg}^{2+}$ at a concentration of $1 \mathrm{mM}$, application of apamin (100 $\mathrm{nM}$ ), an SK channel blocker, during the recovery period had a dramatic influence on the duration of the LTP induced by a single train of high-frequency stimulation $(100 \mathrm{~Hz}, 1 \mathrm{sec})$ (Fig. $1 \mathrm{~A})$. In the control situation, a single train elicited an initial potentiation of the slope of the field excitatory postsynaptic potential (fEPSP) reaching $177 \% \pm 9 \%(\mathrm{n}=5$, mean \pm SEM). Four hours later, it was reduced to $111 \% \pm 7 \%$ of baseline, a level not significantly different from preinduction level (paired Student's $t$-test, $P=0.09)$. In contrast, when apamin was present during recovery, a single train applied 45 min after the end of apamin application induced a strong and long-lasting LTP. The initial potentiation was $249 \% \pm 7 \%(\mathrm{n}=6)$. Over the next $20 \mathrm{~min}$ it diminished to $176 \% \pm 3 \%$ and then remained nearly stable, being as high as $169 \% \pm 7 \% 4 \mathrm{~h}$ after LTP induction, a value significantly higher than that measured in the absence of apamin (Student's $t$-test, $111 \% \pm 7 \%, P<0.05$ ).

\section{Apamin-triggered delayed facilitation of L-LTP induction is a metaplastic phenomenon}

The fact that L-LTP induction was facilitated 45 min after stopping apamin application suggested that this effect was a meta-

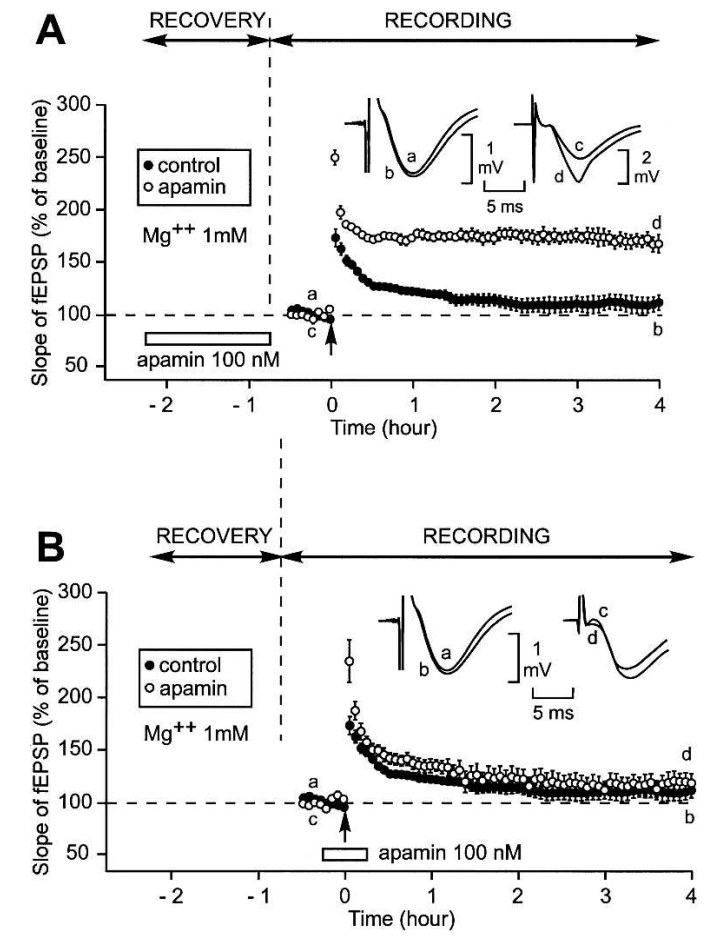

Figure 1. Induction by a single train of high-frequency stimulation (100 Hz, $1 \mathrm{sec}$ ) (HFS) of a long-lasting LTP (L-LTP) instead of a shortlasting LTP (S-LTP) when apamin, an SK channel blocker, was applied during the recovery period but not when it was perfused around the time of LTP induction. $(A)$ Slices were allowed to recover in interface and recordings were also carried out in interface. The figure shows the time course of the fEPSP slope 32 min before and $4 \mathrm{~h}$ after LTP induction by a single train (arrow) in the control situation ( $)$ and when apamin was applied during the recovery period $(O)$. (Inset) Sample fEPSP traces from individual experiments are shown; they were recorded just before $(a, c)$ and $4 \mathrm{~h}$ after $(b, d)$ the induction stimulation. Traces $a$ and $b$ were recorded in the control situation; $c$ and $d$ were recorded when apamin was applied during recovery. (B) Time course of fEPSP slope 32 min before and $4 \mathrm{~h}$ after delivery of 1-sec stimulation train in the control situation (-) and when apamin was applied 15 min before and 15 min after LTP induction (O). (Inset) Labeling similar to that used in A. (Left) A control experiment, (right) an experiment where apamin was applied around LTP induction. plastic phenomenon. However, because apamin is known to induce a long-lasting block of SK channels (Scuvée-Moreau et al. 2002), the aforementioned apamin-triggered facilitation of L-LTP induction could have been due to the persistence of the SK channel block at the moment of LTP induction. We ruled out this possibility. In a first experiment, apamin (100 nM) was applied not before but around the moment of LTP induction (Fig. 1B). Like in the control situation, in presence of apamin, a single train induced a short-lasting LTP. Immediately after the highfrequency stimulation, the increase in the slope of the fEPSP was greater in the presence of apamin $(\mathrm{n}=7)$ than in its absence $(230 \% \pm 11 \%$ vs. $177 \% \pm 9 \%, P<0.05)$. However, this facilitation was only temporary. Four hours after induction, the increase in the fEPSP slope was not different in the presence or in the absence of the drug $(114 \% \pm 7 \%$ vs. $111 \% \pm 7 \%, P=0.94)$. Given that recording (as well as recovery) occurred in an interface chamber with aCSF perfused at a relatively low perfusion rate (1 $\mathrm{mL} / \mathrm{min}$ ), we were concerned that drug wash-in could require more time than we thought. In this case, the apparent lack of action of apamin (15 min after the beginning of its application) could be due to the fact that apamin was not yet fixed to its receptors at the time of LTP induction. To rule out this possibility, we carried out a second control experiment. We allowed the slices to recover in normal aCSF, but switched to apamincontaining aCSF for the entire duration of the field recording (Fig. 2A). Here too, $4 \mathrm{~h}$ after induction, the increase in the fEPSP slope was not different in the presence or absence of the drug $(114 \% \pm 10 \%$ vs. $111 \% \pm 7 \%, P=0.8)$. In a third experiment, we blocked SK channels during the recovery period using (+)methyl-laudanosine, a blocker whose action is fully reversible after $10 \mathrm{~min}$ of washout (Scuvée-Moreau et al. 2002; J. ScuvéeMoreau, J.-F. Liégeois, and V. Seutin, unpubl.). When (+)-methyllaudanosine $(300 \mu \mathrm{M})$ was applied during the recovery period, it had an effect similar to that of apamin on the LTP induced 45 min after the end of the recovery (Fig. 2B). In these conditions, the initial potentiation of the slope of the fEPSP reached $259 \% \pm 16 \%(n=5)$. Over the next $20 \mathrm{~min}$ it diminished to $182 \% \pm 10 \%$. It then remained at such a high level until the end of the experiment, being as high as $181 \% \pm 12 \% 4 \mathrm{~h}$ after LTP induction, a value significantly greater than that observed in the absence of $(+)$-methyl-laudanosine $(111 \% \pm 7 \%, P<0.001)$.

Thus, apamin applied during the recovery period has a metaplastic effect on LTP: In this situation, a single train of stimulation triggers an L-LTP instead of an S-LTP.

\section{Delayed facilitation of L-LTP induction by apamin applied during the recording period}

As a next step, we planned to apply apamin not while the slice was still recovering from the trauma from slicing but during the recording period. To work in conditions close to those used in the initial experiment, where apamin was present during recovery (Fig. 1A), apamin had to be applied for $1 \mathrm{~h} 15 \mathrm{~min}$ after the baseline had been recorded and 45 min before LTP induction (Fig. 3A). However, the long duration ( $2 \mathrm{~h} 30 \mathrm{~min})$ of the period prior to LTP induction associated with the usage of a concentration of $\mathrm{Mg}^{2+}$ at $1 \mathrm{mM}$ modified the properties of the control LTP. In these conditions, a single train induced a long-lasting LTP instead of a short-lasting one $(n=8)$. Three hours after induction, the increase in the slope of the fEPSP was still as high as $142 \% \pm 8 \%$ (Fig. 3A). It would have been surprising if apamin had improved such a robust LTP. It did not. Three hours after induction, the fEPSP was as high as $149 \% \pm 16 \%$, a level not statistically different from that recorded in the control situation $(P=0.67)$.

To investigate potential effects of apamin on the induction 

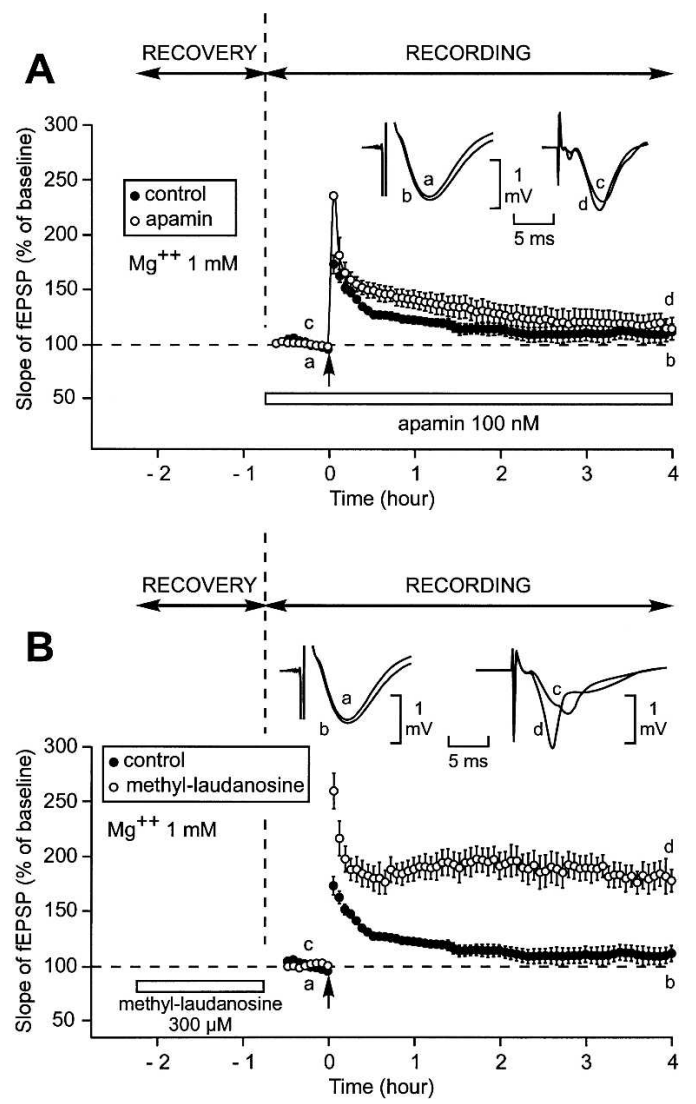

Figure 2. Induction of an L-LTP instead of an S-LTP was not caused by apamin when this drug was applied during the whole recording period but was caused by (+)-methyl-laudanosine, another SK channel blocker, when this drug was applied during the recovery period. Contrarily to that induced by apamin, the SK channel blockage caused by (+)-methyllaudanosine does not resist to a 10-min washout (Scuvée-Moreau et al. 2002; J. Scuvée-Moreau, J.-F. Liégeois, and V. Seutin, unpubl.). (A) Time course of fEPSP slope $32 \mathrm{~min}$ before and $4 \mathrm{~h}$ after delivery of 1-sec stimulation train in the control situation $(\bullet)$ and when apamin was applied during the whole recording period $(O)$. (Inset) Examples of fEPSP recorded in one experiment just before $(a, c)$ and $4 \mathrm{~h}$ after $(b, d)$ induction in the control situation (left) and in presence of apamin (right). (B) Time course of fEPSP slope $32 \mathrm{~min}$ before and $4 \mathrm{~h}$ after delivery of 1-sec stimulation train in the control situation $(\bullet)$ and when (+)-methyllaudanosine was applied during the recovery period $(\bigcirc)$. (Inset) Labeling similar to that used in A. (Left) A control experiment, (right) an experiment where (+)-methyl-laudanosine was applied during the recovery period.

of L-LTP, we had to find conditions where a single train triggered an S-LTP in the absence of apamin. Because we showed in a previous work (Capron et al. 2006) that a small change in $\mathrm{Mg}^{2+}$ concentration (from $1.0 \mathrm{mM}$ to $1.3 \mathrm{mM}$ ) could have a surprisingly dramatic influence on metaplasticity, we repeated the experiment, this time using slices bathed in aCSF containing 1.3 $\mathrm{mM} \mathrm{Mg}^{2+}$ (Fig. 3B). In these conditions, the LTP triggered by a single train $2 \mathrm{~h} 30 \mathrm{~min}$ after the end of the recovery period was much less robust than when the $\mathrm{Mg}^{2+}$ concentration was $1.0 \mathrm{mM}$ (Fig. 3A). Three hours after LTP induction, the slope of the fEPSP was as low as $125 \% \pm 6 \%(n=14)$. In contrast, when the apamin perfusion lasted from $2 \mathrm{~h}$ to $45 \mathrm{~min}$ before LTP induction, a single train caused a long-lasting LTP (Fig. 3B). Immediately after the stimulus application, the slope of the fEPSP reached $248 \% \pm 11 \%(\mathrm{n}=8)$. Afterward, it diminished rapidly to a level of $174 \% \pm 5 \% 20 \mathrm{~min}$ later. It then ceased to decrease and was still as high as $167 \% \pm 5 \% 3 \mathrm{~h}$ after the train application, a value statistically different from the control $(125 \% \pm 6 \%, P<0.001)$.
The facilitating effect of prior application of apamin on induction of long-lasting LTP occurred within a specific time window. When apamin was applied $1 \mathrm{~h}$ before LTP induction it had no facilitating influence (Fig. 3C). Three hours after the train delivery the increase in the slope of the fEPSP was similar whether apamin was perfused or not $(131 \% \pm 9 \%[n=5]$ vs. $125 \% \pm 6 \%[n=5])$.

Influence of apamin on the depolarization induced by the stimulation train.

In the CA1 region, the field depolarization recorded during a train of high-frequency stimulation $(100 \mathrm{~Hz}, 1 \mathrm{sec})$ consists of a succession of fEPSPs, whose amplitudes decrease rapidly to $\sim 10 \%$
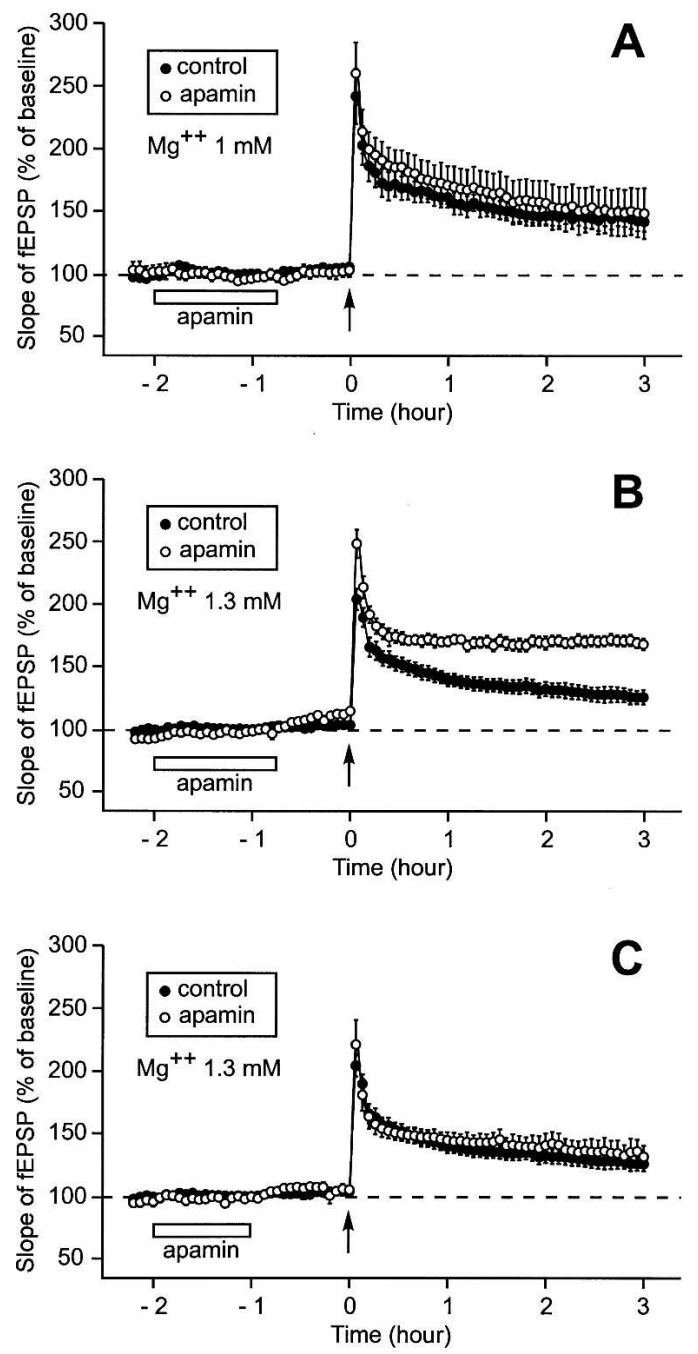

Figure 3. Effect of prior application of apamin on the duration of LTP when the pre-LTP induction duration was as long as $2 \mathrm{~h} 30 \mathrm{~min}$ (after the recovery period). Each part of the figure compares the time course of the fEPSP slope $2 \mathrm{~h} 15$ min before and $3 \mathrm{~h}$ after the delivery of a single train of HFS. (A) When $\mathrm{Mg}^{2+}$ concentration was $1 \mathrm{mM}$, an application of apamin lasting $1 \mathrm{~h} 15 \mathrm{~min}$ and ending $45 \mathrm{~min}$ before LTP induction did not modify the characteristics of LTP. In fact, the control LTP was improved as a result of the longer duration of the baseline. Compare this control LTP with that displayed in Fig. 1A. (B) When $\mathrm{Mg}^{2+}$ concentration was $1.3 \mathrm{mM}$, the duration of LTP was increased by prior application of apamin (with respect to the control LTP recorded at that $\mathrm{Mg}^{2+}$ concentration). (C) When $\mathrm{Mg}^{2+}$ concentration was $1.3 \mathrm{mM}$ and when application of apamin was stopped $1 \mathrm{~h}$ before LTP induction (instead of $45 \mathrm{~min}$ in B), prior application of apamin no longer had any influence on LTP.

\section{Learning \& Memory} www.learnmem.org 

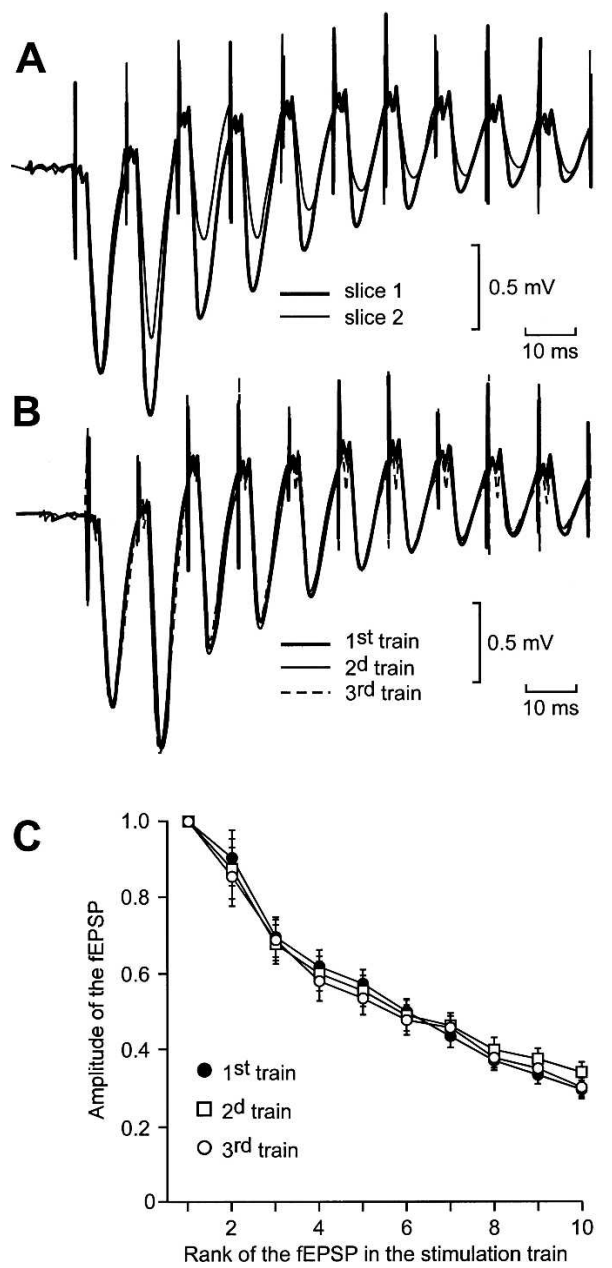

Figure 4. The profile of the global depolarization induced by an HFS train varied from one slice to another $(A)$ but not when the stimulus was delivered thrice at 30-min intervals on the same slice $(B, C)$. $(A)$ Superimposition of the first 10 fEPSPs of two series of fEPSPs recorded in two distinct slices in response to the delivery of one train of HFS. The intensity was adjusted so that the amplitudes of the first fEPSP were the same in slice number 1 (thick trace) as in slice number 2 (thin trace). (B) Superimposition of the global depolarizations induced in a same slice by three HFS trains separated by 30 min. The intensity of stimulation was adjusted to obtain the same amplitude for the first fEPSP in each of the three global depolarizations. (C) In each slice from a group of 10, the amplitude of each of the first 10 fEPSPs elicited by three HFS trains at 30-min intervals was measured. The means \pm SEM of the measurements were plotted in function of the rank of the corresponding fEPSP in the series.

of the first response at the tenth electrical shock (Fig. 4A). SK2 channels have recently been demonstrated to be located in the dendritic spines of the hippocampal pyramidal neurons (NgoAnh et al. 2005), where they are in close vicinity to the NMDA receptors. Therefore, it can be anticipated that, when a synapse is stimulated repetitively at high frequency, the $\mathrm{Ca}^{2+}$ influx associated with an EPSP would trigger the opening of the SK channels, which would shunt the next EPSP and hence decrease its amplitude. Consequently, apamin should increase the global depolarization induced by a train of stimulation.

Here, we studied the influence of apamin on the field depolarization induced by a high-frequency stimulation (HFS) train. As illustrated in Figure 4A, the profile of the global depolarization induced by an HFS train varied significantly from one slice to another. Therefore, we decided to test the influence of apamin by comparing the global depolarizations induced in a same slice during and after apamin application with that obtained in the absence of the drug. In a control experiment, we ascertained that, in absence of the drug, the three global depolarizations induced in the same slice by three trains of HSF delivered $>30$ min apart were the same (Fig. 4B). For relevant comparisons, the intensity of stimulation was adjusted so that the amplitudes of the first fEPSPs of the three-fEPSP series recorded from the same slice were the same. In a control group of 10 slices, the amplitudes of each of the first 10 fEPSPs were measured in the response to each of the three HFS trains (Fig. 4C). The total depolarization induced was the same in the three situations (two-way ANOVA with one repeated measure, $\left.F_{(2,27)}=0.05, P=0.95\right)$.

The effect of apamin, applied for $1 \mathrm{~h} 15 \mathrm{~min}$, was then tested on two other groups of slices. In a first group of eight slices, an HFS train was delivered before apamin application, at the 45th min of the drug perfusion and $45 \mathrm{~min}$ after apamin treatment (Figs. 5B, 6A). In a second group of six slices, an HFS train was delivered before, during (at the 15th $\mathrm{min}$ ), and after (60 min) apamin application (Figs. 5A,C, 6B). As illustrated in Figure 5, the global depolarization induced by a stimulation train was increased not only during (Fig. 5A) but also after (Fig. 5B) apamin
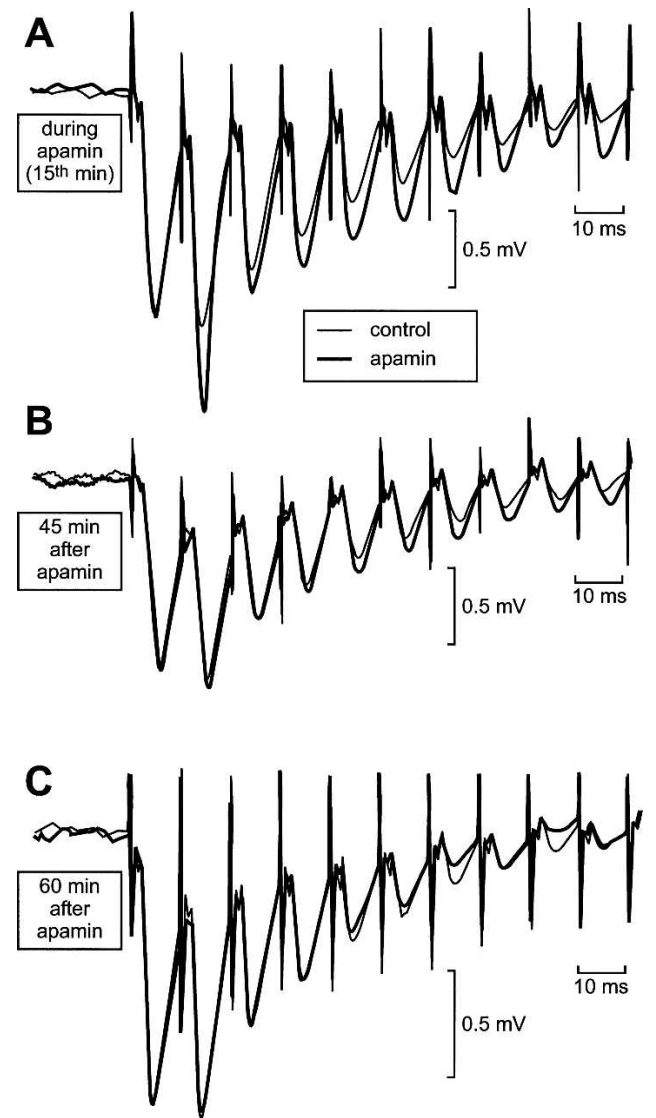

Figure 5. Apamin causes an enhancement of the global depolarization induced by a train of HFS $(100 \mathrm{~Hz})$. After recovery and $15 \mathrm{~min}$ of baseline recording, apamin was applied for $1 \mathrm{~h} 15 \mathrm{~min}$. $(A, B, C)$ Each part of the figure compares the first 10 fEPSPs of two series of fEPSPs recorded on a same slice in response to the delivery of one train of HFS, one under the influence of apamin (thick traces), the other before any application of the drug (thin traces). (A) The global depolarization induced by the stimulation train was increased in presence of apamin (here at the 15th min after the start of the apamin perfusion). (B) The global depolarization induced by the stimulation train was still increased 45 min after the end of the application of apamin. (C) The global depolarization was no longer increased when elicited 60 min after the application of apamin had been stopped. 

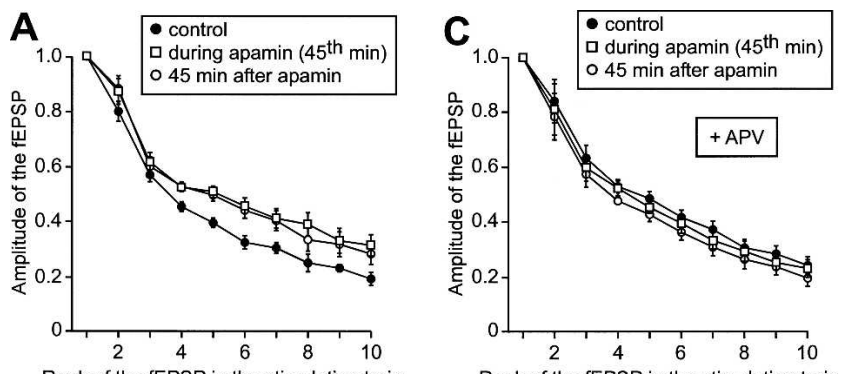

Rank of the fEPSP in the stimulation train
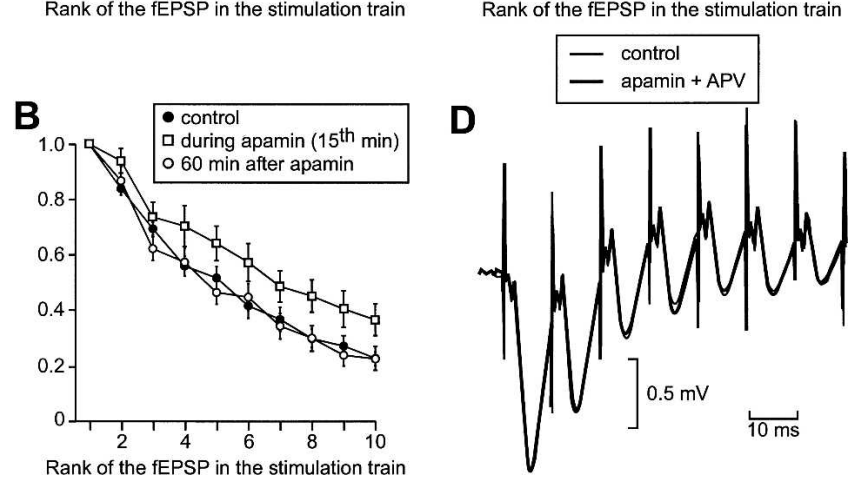

Rank of the fEPSP in the stimulation train depolarization elicited by a train of high-frequency stimulation, and this phenomenon is NMDA receptor-dependent. $(A, B, C)$ The amplitude of each of the first $10 \mathrm{fEPSPs}$ within the series of fEPSPs is plotted in function of its rank in the series. $(A)$ Amplitudes of the fEPSPs induced by a stimulation train in a same group of six slices before apamin application, at the 45th min of the drug application, and $45 \mathrm{~min}$ after the end of apamin application. (B) Same display as in $A$, but the stimulation trains were applied on another set of eight slices before, 15 min after the start, and 60 min after the end of apamin perfusion. (C) Same display and same pattern of train delivery on another set of five slices, as in $A$, but when APV was present throughout the experiment. $(D)$ Illustration of the lack of effect of apamin on the global depolarization induced by a highfrequency stimulation train when APV was coapplied with apamin. The first seven fEPSPs of two series of fEPSPs elicited before (thin trace) and 45 min after apamin application are superimposed.

application. However, this effect was no longer observed $1 \mathrm{~h}$ after apamin treatment (Fig. 5C). In the group of six slices, the total depolarization induced was increased during (45th $\mathrm{min}$ ) and after the end of (45 min) apamin application (two-way ANOVA with one repeated measure, $F_{(2,15)}=4.1, P<0.05$, followed by post hoc analysis, Fig. 6A). In the group of eight slices, the total depolarization recorded at the 15 th min of apamin application was greater than in the control, but that observed $1 \mathrm{~h}$ after apamin application was not different from the control (two-way ANOVA with one repeated measure, $F_{(2,21)}=3.1, P<0.05$, followed by post hoc analysis, Fig. 6B).

These results show that the blockage of SK channels induced by apamin was already fully developed $15 \mathrm{~min}$ after the beginning of apamin application and persisted $\sim 45$ min after the washout of the drug. We interpreted the difference between the experimental results displayed in Figure 1, A and B, as a piece of evidence in favor of the metaplastic nature of the action of apamin on LTP. As aforementioned, the possibility that the apamin molecules had not yet reached their sites on the SK channels after only 15 min of apamin application could cast doubt on this interpretation. This doubt was not justified. Indeed, the fact that the depolarization induced by the stimulation train was already increased only $15 \mathrm{~min}$ after the start of the drug application proved that, at that time, the apamin molecules were already attached to their receptor sites.

The dependence of the apamin-induced increase in depolar- ization on the influx of $\mathrm{Ca}^{2+}$ though the NMDA receptors was confirmed in experiments where APV was applied throughout the experiment, before, during, and after apamin application. As APV prevented any $\mathrm{Ca}^{2+}$ influx through the NMDA receptors, there was no opening of the SK channels during a stimulation train, no matter when it was applied-before, during, or after apamin application. This phenomenon clearly emerges from the comparison of Figure 6C with Figure 6A. Under APV $(n=5)$, there was no difference between the total depolarizations recorded before, during (45th min), and after the end of (45 min) apamin treatment (Fig. 6C, two-way ANOVA with one repeated measure, $\left.F_{(2,12)}=1.8, P=0.2\right)$.

\section{Delayed facilitation of L-LTP induction by apamin is NMDA receptor-dependent}

When APV, a blocker of NMDA receptors, was applied together with apamin, the delayed effect of apamin on LTP was suppressed (Fig. 7A). In these conditions, the LTP induced by a single train of stimulation was an S-LTP, as was the case where no drug was applied. Three hours after induction, the slopes of the fEPSP were similar in the control situation $(125 \% \pm 6 \%, \mathrm{n}=14)$ and when apamin and APV were previously co-applied $(109 \% \pm 10 \%, \mathrm{n}=5$, Mann-Whitney rank sum test, $P=0.18)$. We ascertained that $45 \mathrm{~min}$ after its application, APV on its own had no effect (Fig. 7B). Three hours after induction, the slopes of fEPSP were not different, whether APV had been applied $(117 \% \pm 6 \%, \mathrm{n}=4)$ or not $(125 \% \pm 6 \%, \mathrm{n}=14, P=0.15)$. Thus, we found that the metaplastic effect of apamin on L-LTP induction was NMDA receptor-dependent.

\section{Apamin did not have any delayed influence on the NMDA receptor-mediated fEPSP}

Prior application of apamin led to facilitated L-LTP induction. One possibility that could explain these results was an increased
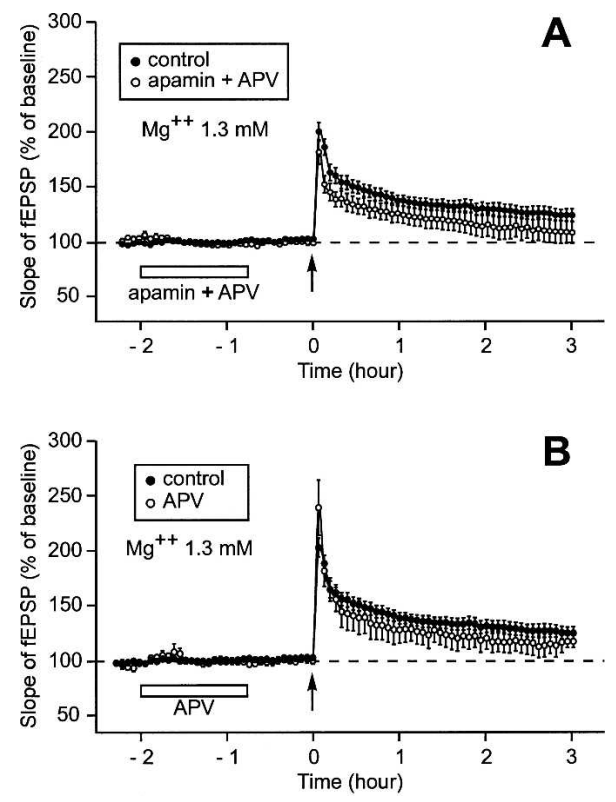

Figure 7. Suppression of the metaplastic effect of apamin on LTP by APV. $(A, B)$ Time course of fEPSP $2 \mathrm{~h} 15 \mathrm{~min}$ before and $3 \mathrm{~h}$ after one train of HFS. $(A)$ When APV was coapplied with apamin, the LTP induced after prior application of apamin (O) was not different from the control LTP $(\bullet)$. (B) When APV was applied alone using the same timing as that used for apamin application, the LTP induced after prior application of APV $(\bigcirc)$ was not different from the control LTP $(\bullet)$. 
efficacy of the NMDA receptors at the moment of LTP induction. To put this hypothesis to the test, we compared the fEPSP mediated by the NMDA receptors when apamin was previously applied and when it was not. The fEPSP recorded in the CA1 region in response to a stimulation of the Schaffer collaterals consists of a large, AMPA-receptor-mediated, and a small, NMDA receptormediated, component. At rest, the opening of NMDA receptors under the action of glutamate is hindered by the presence of $\mathrm{Mg}^{2+}$ ions in their ionic channels. It is thus possible to record the NMDA receptor-mediated component of the fEPSP by blocking the AMPA receptors using CNQX $(20 \mu \mathrm{M})$. It is also possible to measure an enhanced NMDA receptor-mediated component of the fEPSP by lifting the $\mathrm{Mg}^{2+}$ blockage using aCSF free of $\mathrm{Mg}^{2+}$ and containing CNQX. The fEPSPs of two groups of eight slices each were compared, one submitted to apamin, the other not. CNQX was applied for $20 \mathrm{~min}$ after apamin perfusion (where applied). At the end of this period the input/output relationship of the NMDA-mediated fEPSP [f(NMDA) EPSP] was established (Fig. 8A). At every tested stimulation intensity, the f(NMDA) EPSP amplitudes were not different whether apamin was applied previously or not (Student's $t$-test, $P>0.05$ ). After the end of the 20-min application of CNQX, aCSF free of $\mathrm{Mg}^{2+}$ containing CNQX was perfused. Around $40 \mathrm{~min}$ after the end of prior application of apamin (where applied), the input-output relationships
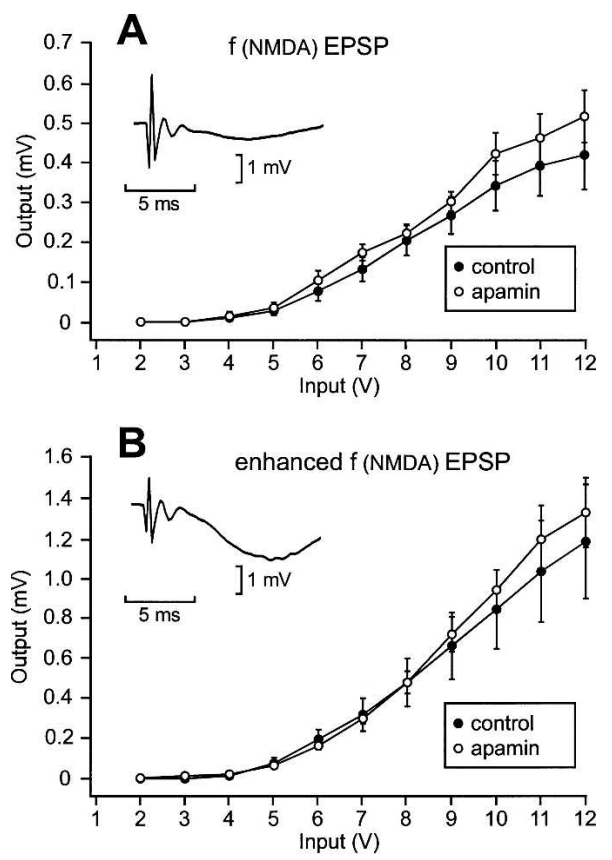

Figure 8. Apamin did not produce any delayed change in the NMDA receptor-mediated fEPSP. (A) Amplitude of the NMDA receptor-mediated fEPSP in function of the stimulation intensity in the control situation (-) and 20 min after the end of apamin application $(\bigcirc)$. Apamin was applied for $1 \mathrm{~h} 15 \mathrm{~min}$. The NMDA receptor-mediated component of the fEPSP was obtained in response to stimulation pulses delivered to the Schaffer collaterals of slices perfused for 20 min with aCSF containing CNQX, a blocker of AMPA receptors. (Inset) Sample trace of an NMDA receptormediated fEPSP recorded during an individual experiment. (B) Amplitude of the enhanced NMDA receptor-mediated fEPSP in function of the stimulation intensity in the control situation $(\bullet)$ and $40 \mathrm{~min}$ after the end of apamin application $(\bigcirc)$. After completion of the measurements summarized in $A$, the same slices were perfused with CNQX dissolved in $\mathrm{Mg}^{2+}$-free aCSF. This lifted the $\mathrm{Mg}^{2+}$ blockage in the NMDA receptors, so that all the NMDA receptors could be activated by glutamate. (Inset) Sample trace of an enhanced NMDA receptor-mediated fEPSP recorded during the same individual experiment as that shown in the inset of $A$.
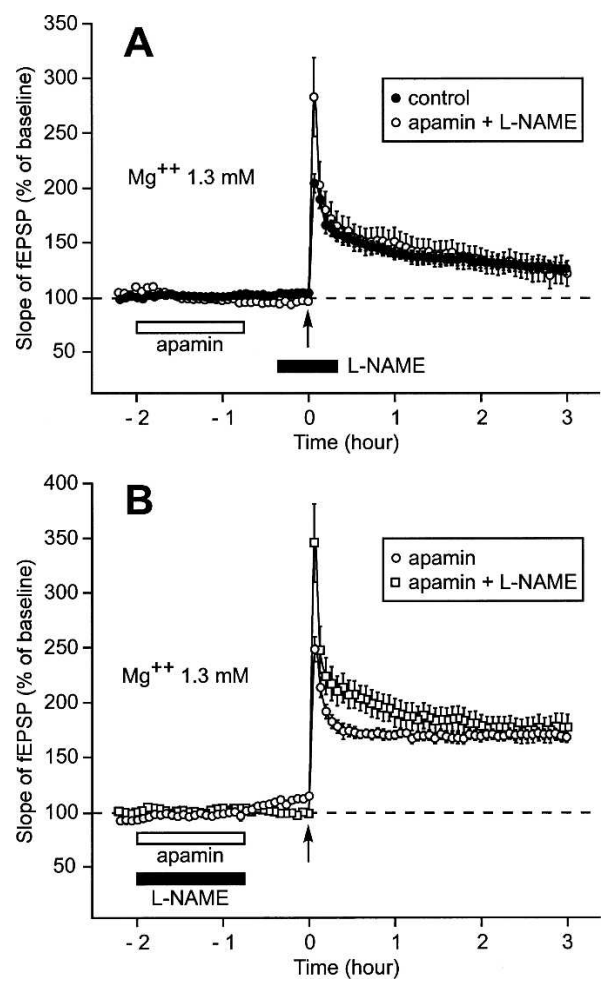

Figure 9. NO-synthase signaling pathway is necessary for the expression of the metaplastic effect of apamin on LTP. ( $A$ ) When L-NAME, an inhibitor of NO-synthase, was applied $20 \mathrm{~min}$ before and $20 \mathrm{~min}$ after LTP induction, it prevented prior application of apamin from transforming the S-LTP usually triggered by a single stimulation train into an L-LTP. In this case, the time course of the increase in the slope of the fEPSP triggered by one train of HFS delivered after prior application of apamin (O) was not different from that observed when no drug was applied (O). (B) When L-NAME was coapplied with apamin, it did not prevent apamin from having a metaplastic effect on LTP. In this case, the time course of the increase in the slope of the fEPSP triggered by a single stimulation train corresponded to the profile of an L-LTP whether apamin was applied 45 min before LTP induction with L-NAME ( $\square$ ) or without $(\bigcirc)$.

of the enhanced $\mathrm{f}(\mathrm{NMDA})$ EPSPs were established (Fig. 8B). At every tested stimulation intensity, the enhanced f(NMDA) EPSPs were not statistically different, either $(P>0.05)$. This suggests that there was no major delayed modification of the NMDA receptors induced by prior application of apamin.

The delayed effect of apamin on L-LTP induction is mediated by the NO-synthase signaling pathway LTP depends on activation by $\mathrm{Ca}^{2+} /$ calmodulin of several signaling pathways, among which is the NO-synthase pathway. Here, we tested whether or not the delayed action of apamin on LTP was dependent on this pathway. When L-NAME, an inhibitor of NO-synthase, was applied around the moment of LTP induction, prior application of apamin did not increase the duration of LTP (Fig. 9A). Three hours after induction, the increase of the fEPSP slope was $122 \% \pm 12 \%(n=6)$, a level not different from that reached in the control situation (Fig. 3B, 125\% $\pm 6, P=0.59$ ). Interestingly, L-NAME had no effect when co-applied with apamin (Fig. 9B). Three hours after induction, the slope of the fEPSP was still as high as $176 \% \pm 5 \%(n=5)$, a level not different from that observed when apamin was applied alone (Fig. 3B, $167 \% \pm 5 \%, P=0.5$ ), but significantly greater than that reached in the control situation $(P<0.001)$. 


\section{Delayed action of apamin on paired-pulse facilitation:} A second metaplastic effect of apamin

We next explored how paired-pulse facilitation, known to be due to a presynaptic mechanism, was affected by apamin. Thirty minutes after the end of the recovery period, six slices of a first group were submitted to apamin for $1 \mathrm{~h} 15 \mathrm{~min}$, whereas five slices of a control group were perfused with plain aCSF. Schaffer collaterals were stimulated using a paired-pulse with a 25 -msec interval before apamin application (5 min), during apamin perfusion (at the 60th min), and after the end of apamin treatment (at the 16th $\mathrm{min}$, 36th $\mathrm{min}$, and 56th $\mathrm{min}$ ). The same paired-pulses were delivered at the corresponding times on the control slices. In the control situation, the initial paired-pulse facilitation in the slope of the fEPSP was $164 \% \pm 5 \%(n=6)$ and remained unchanged over time (one-way ANOVA with one repeated measure, $F=0.39$, $P=0.81$, Fig. 10A, black columns). In the group of slices treated with apamin, the initial paired-pulse facilitation in the slope of


C

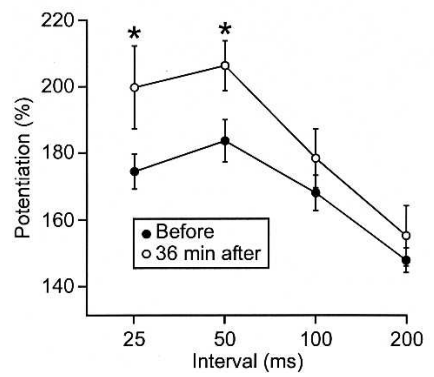

D

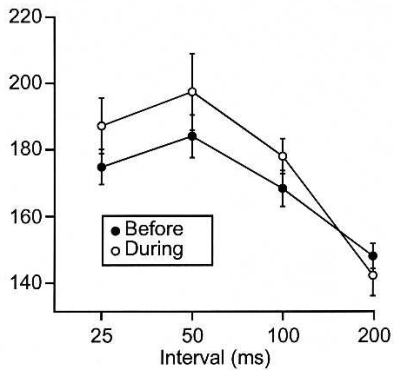

Figure 10. Delayed influence of apamin on paired-pulse facilitation. (A) Influence of apamin (applied for $1 \mathrm{~h} 15 \mathrm{~min}$ ) on the amplitude of pairedpulse facilitation tested with a 25 -msec interval (empty columns). ( ${ }^{*}$ ) A significant difference with respect to the measurement made before apamin application. The moment of testing is indicated under each column. When paired-pulse facilitation was measured in the absence of apamin application at the corresponding time points (black columns), the amplitude of the potentiation did not change over time. (aCSF) Artificial cerebrospinal fluid. (Inset) fEPSP elicited by paired-pulses separated by an interval of $25 \mathrm{msec}$. (B) The influence of apamin on paired-pulse facilitation was suppressed by APV. The testing pattern was the same as in $A$. (C) Amplitude of the paired-pulse facilitation in function of the interval separating the paired-pulses before $(\bullet)$ and $36 \mathrm{~min}$ after apamin application $(O)$. (D) Amplitude of the paired-pulse facilitation in function of the interval separating the paired-pulses before $(\bullet)$ and at the 60th min of apamin application $(\bigcirc)$. the fEPSP was $175 \% \pm 5 \%(n=6)$. Under the influence of apamin it increased (Fig. 10A, white columns, one-way ANOVA with one repeated measure, $F=3.96, P<0.05$ ). Paired comparisons using the Student-Newman-Keuls method showed that there was no significant increase during apamin perfusion (at the 60 th $\mathrm{min}$ ), whereas there was indeed a significant increase after apamin application $(196 \% \pm 14 \%$ at the 16 th $\min$ and $200 \% \pm 12 \%$ at the 36 th min). The fact that apamin had no immediate action on paired-pulse facilitation but that it did have a delayed one indicated that we were facing another metaplastic phenomenon. Interestingly, 56 min after apamin application, at a time when apamin did not influence LTP any more, pairedpulse facilitation fell back to a level not statistically different from that measured before apamin application.

Like the metaplastic effect of apamin on LTP, the metaplastic action of apamin on paired-pulse facilitation was NMDA receptor-dependent. APV on its own did not modify the pairedpulse facilitation $(152 \% \pm 3 \%[n=8]$ vs. $149 \% \pm 2 \%$ in plain cerebrospinal fluid [aCSF], paired Student's $t$-test, $P=0.46$ ). When apamin was added in aCSF containing APV, the pairedpulse facilitation did not change under the influence of apamin (Fig. 10B, gray columns) (one-way ANOVA with one repeated measure, $F=1.67, P=0.15$ ).

Moreover, other stimulation intervals were also tested: Paired shocks with an interpulse interval of $50 \mathrm{msec}, 100 \mathrm{msec}$, and $200 \mathrm{msec}$ were delivered, respectively, $1 \mathrm{~min}, 2 \mathrm{~min}$, and 3 min after the paired-pulses with an interval of $25 \mathrm{msec}$. Pairedpulse facilitation was also increased after apamin application when the interpulse interval was $50 \mathrm{msec}$ but not when it was longer (Fig. 10C, Student's $t$-test, $P<0.05$ ). During apamin treatment, paired-pulse facilitation was not significantly changed for any tested interpulse intervals (Fig. 10D, Student's t-test, $P<0.05)$.

\section{Discussion}

The main findings of this work are the following: (1) Apamin, an SK channel blocker, has a metaplastic effect on LTP (see the summary bar graph of Fig. 11A). Forty-five minutes after the end of apamin application, a single train of high-frequency stimulation (HSF) induces a long-lasting LTP (L-LTP) instead of a short-lasting one (S-LTP). In contrast, the presence of apamin around the time of LTP induction does not induce any change in the duration of the triggered LTP. (2) The metaplastic effect of apamin on LTP is mediated by NMDA receptors and is crucially dependent on the NO-synthase pathway (see the summary bar graph of Fig. 11B). (3) Apamin also has a metaplastic effect on paired-pulse facilitation (PPF). PPF is increased after drug application but not during it. This metaplastic effect is also mediated by NMDA receptors. (4) Apamin causes an increase in the global depolarization induced by a train of high-frequency stimulation $(100 \mathrm{~Hz}, 1 \mathrm{sec})$. This effect is not a metaplastic one. It is fully developed during apamin application (as soon as $15 \mathrm{~min}$, if not sooner, after the start of apamin treatment) and persists $\sim 45$ min after the beginning of the washout of the drug.

\section{The delayed actions of apamin are metaplastic effects}

The term metaplasticity refers to the fact that synaptic plasticity is sensitive not only to the "state" imposed by extra factors at the moment of induction, but also to the "state" created by certain factors prior to the induction (Abraham and Bear 1996; Abraham and Tate 1997). The starting point of this work consisted of a pair of experiments. In Experiment 1, 45 min after apamin application, a single HFS train induced an L-LTP instead of an S-LTP (Fig. 1A). In contrast, in Experiment 2, when a single HFS train was 

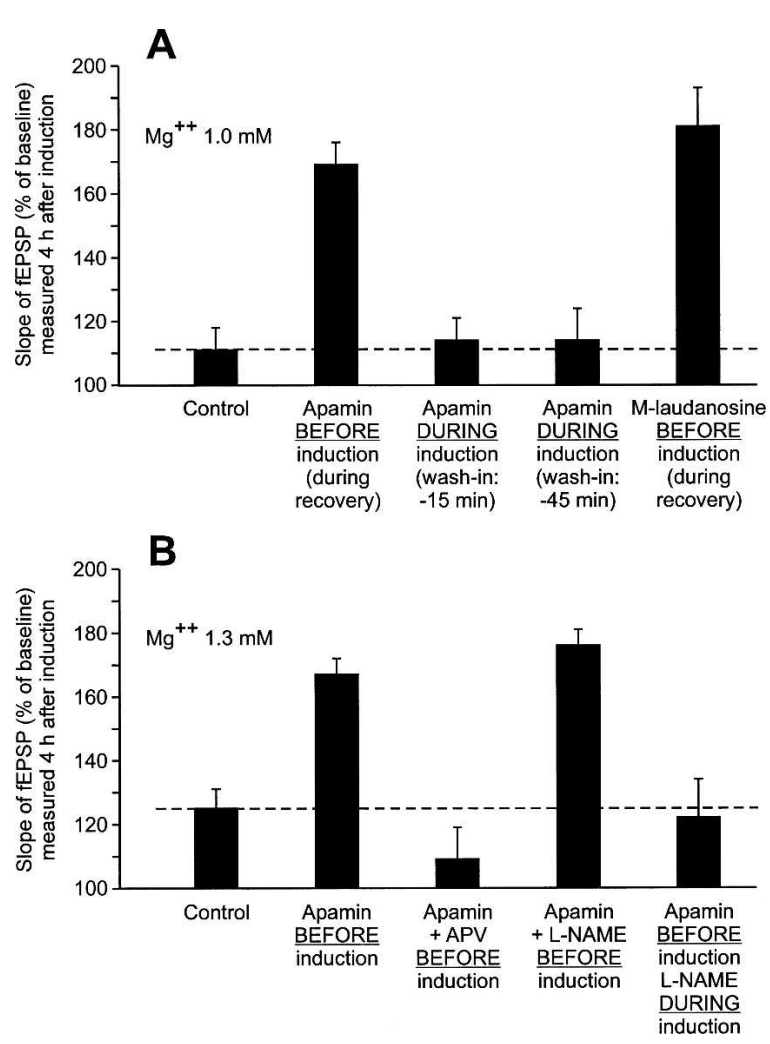

Figure 11. Summary bar graph gathering the results of experiments carried out to demonstrate that the effect of apamin on LTP was metaplastic $(A)$ and to try to-at least partially-elucidate the mechanisms of this action $(B)$. (A) This set of experiments was carried out using aCSF containing $\mathrm{Mg}^{2+} 1 \mathrm{mM}$. The amplitude $( \pm \mathrm{SEM})$ of the increase in the slope of fEPSP was measured $4 \mathrm{~h}$ after LTP induction. (B) In this second set of experiments, the concentration of $\mathrm{Mg}^{2+}$ was $1.3 \mathrm{mM}$ and the measurements were made $3 \mathrm{~h}$ after LTP induction.

delivered during apamin application (at the 15th min), like in the control situation, it triggered an S-LTP (Fig. 1B).

Because recordings were made in an interface chamber while the slices were perfused at a relatively low perfusion rate (1 $\mathrm{mL} / \mathrm{min}$ ), one had to ascertain that the negative result of Experiment 2 was not due to the fact that the drug had not yet reached its target $15 \mathrm{~min}$ after beginning the apamin perfusion. This was ruled out in two ways. First, the negative result of the experiment was confirmed when apamin was perfused during the whole recording period, and thus for 45 min before LTP induction. Second, the fact that the global depolarization triggered by an HFS train was already well established at the 15 th min of apamin perfusion proved that SK channels were already blocked at the time of LTP induction in Experiment 2.

The mechanism of the positive result of Experiment 1 could also be questioned. Indeed, apamin is known to induce a longlasting blockage of SK channels. In this work, we assessed the blockage of SK channels by measuring a consequence of it, the increase in the global depolarization elicited by an HFS train. This effect was already present at the 15 th $\min$ of apamin perfusion (see above) and persisted $\sim 45$ min after the end of the drug application. It was thus tempting to ascribe the delayed effect of apamin on LTP to the long-lasting blockage of SK channels. However, if the apamin-induced transformation of an S-LTP into an L-LTP was directly due to this phenomenon, it should have been observed after $15 \mathrm{~min}$ of apamin perfusion, which was not the case. Another piece of evidence comes from the fact that (+)methyl-laudanosine, whose blocking effect on SK channels dis- appeared after 10 min of washout (Scuvée-Moreau et al. 2002; J. Scuvée-Moreau, J.-F. Liégeois, and V. Seutin, unpubl.), also caused an increase in the duration of LTP when it was triggered $45 \mathrm{~min}$ after the end of the drug perfusion.

Therefore, the results of Experiments 1 and 2 strongly suggest that the delayed action of apamin on LTP is a novel form of metaplasticity. This is not the first time that metaplastic phenomena concerning the duration of LTP have been reported. Woo and Nguyen (2002) found that when four trains of HFS were preceded $7 \mathrm{~min}$ earlier by the application of a train of lowfrequency stimulation ( $3 \mathrm{~min}, 5 \mathrm{~Hz}$ ), multiple trains induced an S-LTP instead of an L-LTP. Conversely, we recently reported that a single train of HFS induced an L-LTP instead of an S-LTP when the recovery of the slices occurred in submersion instead of in interface (Capron et al. 2006)

Similarly, the fact that apamin caused an increase in pairedpulse facilitation $16 \mathrm{~min}$ and $36 \mathrm{~min}$ after its application, whereas it left PPF unchanged during its application, shows that the action of apamin on PPF is also a metaplastic phenomenon.

\section{Potential molecular mechanisms of apamin-induced metaplasticity}

As far as the underlying molecular mechanisms are concerned, two questions arise. First, how can the action of apamin on SK channels induce, 45 min later, an enhancement of the maintenance of an LTP and an increase in the paired-pulse facilitation? Second, what is the role of the NMDA receptors in triggering this phenomenon?

The mechanisms of LTP are complex (Collingridge et al. 1983; Lynch et al. 1983; Frey et al. 1993; Nguyen et al. 1994; Abel et al. 1997; Giese et al. 1998; Kandel 2001). Basically, during LTP induction, $\mathrm{Ca}^{2+}$ enters postsynaptic spines through the NMDA receptors. Next, the newly entered $\mathrm{Ca}^{2+}$ links to calmodulin $(\mathrm{CaM})$, and the complex $\mathrm{Ca}^{2+} / \mathrm{CaM}$ activates several enzymes, among which are CaMKII, adenylate cyclase, and NO synthase (O'Dell et al. 1991; Haley et al. 1992; Williams et al. 1993; Schuman and Madison 1994; Arancio et al. 1996; Ko and Kelly 1999). Here, we demonstrated that the NO-synthase pathway was crucial for the expression of the metaplastic effect of apamin on LTP (Fig. 9). The fact that the NMDA-mediated fEPSP was unchanged (Fig. 8) strongly suggests that the $\mathrm{Ca}^{2+}$ influx occurring during LTP induction was not changed by prior application of apamin. Therefore, the modified element in the $\mathrm{Ca}^{2+}-\mathrm{Ca}^{2+} /$ CaM-NO-synthase signaling pathway must be at least one step beyond the influx of $\mathrm{Ca}^{2+}$. One possibility is that the affinity of calmodulin for $\mathrm{Ca}^{2+}$ would be increased. This is not impossible. For instance, it is known that the affinity of the CaM molecules constitutively bound to SK channels for $\mathrm{Ca}^{2+}$ (Fanger et al. 1999; Keen et al. 1999; Xia et al. 1998) vary in function of their state of phosphorylation at threonine 80 (Bildl et al. 2004). Moreover, this state of phosphorylation is regulated by a protein kinase (CK2) and a protein phosphatase (PP2A) attached to SK channels. We speculate that it is not impossible that apamin would induce a modification of the CaM molecules attached to SK channels. Over time, this modified CaM could dissociate from the SK channel and play an enhanced role in the $\mathrm{Ca}^{2+}-\mathrm{Ca}^{2+} / \mathrm{CaM}-\mathrm{NO}-$ synthase signaling pathway.

Paired-pulse facilitation (PPF) of central synaptic transmission is primarily due to increased presynaptic glutamate release under the influence of residual calcium (Creager et al. 1980; McNaughton 1982; Muller and Lynch 1989; Manabe et al. 1993; Christie and Abraham 1994; Schulz et al. 1994). However, postsynaptic $\mathrm{Ca}^{+} / \mathrm{CaM}$ signaling pathways can modulate PPF (Wang and Kelly 1996). This involves a $\mathrm{Ca}^{2+} / \mathrm{CaM}$-activated CaMKII pathway leading to an increase in the desensitization of AMPA receptors and likely a $\mathrm{Ca}^{2+} / \mathrm{CaM}$ phosphatase pathway causing a decrease in the desensitization of AMPA receptors (Wang and 
Kelly 1996). Activation of kinases necessitates higher concentrations of $\mathrm{Ca}^{2+} / \mathrm{CaM}$ than activation of phosphatases. For example, the protein phosphatase calcineurin is activated by 450 -fold lower concentrations of $\mathrm{Ca}^{2+} / \mathrm{CaM}$ relative to CaMKII (Mulkey et al. 1994). In the control situation (in absence of apamin), the postsynaptic influx of $\mathrm{Ca}^{2+}$ resulting from a single pulse is probably not sufficient to activate either CaMKII or phosphatases. After prior application of apamin, the hypothesized apamininduced enhanced affinity of $\mathrm{CaM}$ for $\mathrm{Ca}^{2+}$ could lead to an increase in the concentration of $\mathrm{Ca}^{2+} / \mathrm{CaM}$ reached after the first of the paired-pulses. This could be sufficient to activate phosphatases and hence decrease the desensitization of AMPA receptors. Consequently, paired-pulse facilitation could be increased.

Another possible mechanism is worth considering. Apamin, being a blocker of a synaptically located ion channel, might be exerting its metaplastic effects on the synaptogenesis that occurs as a result of slicing (Kirov et al. 1999). However, this is unlikely. Slicing-induced synaptogenesis occurs during $2 \mathrm{~h}$ after preparing the slices and ceases afterward. In contrast, the metaplastic effects of apamin were observed not only when apamin was applied just after slicing (Fig. 1A) but also $2 \mathrm{~h}$ after it (Fig. 3B).

Like a classic metaplastic effect (i.e., stimulation of a synapse at frequencies ranging from 5 to $30 \mathrm{~Hz}$ causes a dramatic reduction in subsequently evoked LTP) (Huang et al. 1992; O'Dell and Kandel 1994; Zhang et al. 2005), the two metaplastic effects of apamin reported here are also dependent on NMDA receptors. This implies that an NMDA receptor-mediated $\mathrm{Ca}^{2+}$ influx is necessary for the induction of the metaplastic phenomena induced by apamin. During apamin application, NMDA receptors were weakly activated due to the glutamate released by test stimulations (when apamin was applied in interface during the recording period) and to that released as a result of the slicing trauma (when apamin was applied during the recovery period). This small $\mathrm{Ca}^{2+}$ influx could activate phosphatases, like PP2Aassociated with the SK channels-and so lead to an enhanced affinity of CaM for $\mathrm{Ca}^{2+}$.

Because of this dependence of the metaplastic effects of apamin on NMDA receptors, we have hypothesized that a postsynaptic mechanism explains the phenomenon. However, as SK3 channels have been found to be located on the presynaptic terminals of cultured hippocampal pyramidal neurons (Obermair et al. 2003), we cannot exclude the possibility that apamin might exert its effect via a presynaptic mechanism.

\section{Influence of apamin on the depolarization induced by a single train}

There is histochemical (Ngo-Anh et al. 2005) and electrophysiological (Faber et al. 2005) evidence showing that SK channels are colocalized with NMDA receptors in dendritic spines of glutamatergic synapses. It can be anticipated that during tetanic stimulation of glutamatergic synapses the $\mathrm{Ca}^{2+}$ that entered through the NMDA receptors during an EPSP would open SK channels and consequently shunt the next EPSP. As a result, the summation of EPSPs during tetanic stimulation is expected to be enhanced when SK channels are blocked by apamin. This was shown to be the case in the lateral amygdala (Faber et al. 2005). In this work, we demonstrated that such a phenomenon occurred in the synapses between the Schaffer collaterals and the CA1 pyramidal neurons. We also confirmed that it was NMDA receptor-dependent, as its development was blocked by APV.

\section{Materials and Methods}

\section{Animals}

Male C57BL/6 mice, aged 6-10 wk (Charles River) were used for all the experiments, which were carried out in accordance with
National Institutes of Health regulations for the care and use of animals in research and with local ethics committee guidelines.

\section{Electrophysiology}

Transverse hippocampal slices (400- $\mu$ m thickness) were prepared as described by Nguyen and Kandel (1997). The hippocampus was isolated and sliced with a Mcllwain chopper. Slices were allowed to recover for $1.5 \mathrm{~h}$ at $28^{\circ} \mathrm{C}$ in interface. After this recovery period all the recordings were made in an interface chamber (FST) at $28^{\circ} \mathrm{C}$. The rate of flow of the perfused liquid was $1 \mathrm{~mL} /$ min. Baseline recording started 15 min later and lasted $30 \mathrm{~min}$. Then LTP was induced electrically by applying a single 1-sec train $(100 \mathrm{~Hz}$, at test strength). Slices were perfused with aCSF of the following composition: $124 \mathrm{mM} \mathrm{NaCl}, 5 \mathrm{mM} \mathrm{KCl}, 26 \mathrm{mM}$ $\mathrm{NaHCO}_{3}, 1.0 \mathrm{mM} \mathrm{NaH}{ }_{2} \mathrm{PO}_{4}, 2.5 \mathrm{mM} \mathrm{CaCl}_{2}$, either 1.3 or $1 \mathrm{mM}$ $\mathrm{MgSO}_{4}, 10 \mathrm{mM}$ glucose. The aCSF was aerated with $95 \% \mathrm{O}_{2}$ and $5 \% \mathrm{CO}_{2}$. Extracellular fEPSPs were recorded with a glass microelectrode (2-5 Mohm, filled with aCSF) positioned in the stratum radiatum of area CA1. A bipolar nickel-chromium stimulating electrode was used to elicit fEPSPs by stimulation of the Schaffer collateral fibers. Stimulation intensity (0.08-msec pulse duration) was adjusted to elicit fEPSP amplitudes that were $\sim 40 \%$ of maximum size. Basal synaptic transmission was assessed by stimulating Schaffer collaterals once per minute at this test stimulation intensity. Slices that showed maximal fEPSPs $<2 \mathrm{mV}$ were rejected.

Apamin (Tocris), 2-amino-5-phosphonopentanoic acid (APV, Acros Organics), and L-NAME (Sigma) were prepared as a concentrated stock solution in $\mathrm{H}_{2} \mathrm{O}$. (+)-Methyl-laudanosine was prepared in DMSO and subsequently diluted at $0.1 \%$ to obtain the final concentration.

\section{Data analysis}

For each slice, the fEPSP slopes were normalized against the average slope over the $30 \mathrm{~min}$ before LTP induction. The statistical significance $(P<0.05)$ of the difference in increase of the fEPSP measured 3 or $4 \mathrm{~h}$ after two different treatments applied to two distinct groups of slices was assessed using a Student's $t$-test. When another test was used, it is indicated in the text.

\section{Acknowledgments}

We thank Christiane Busson for realizing the figures and Ramona Shelby for correcting the English. This investigation was supported by the Queen Elisabeth Fund for Medical Research and by the Belgian Fund for Scientific Research. L.R. is a Research Associate at the Belgian Fund for Scientific Research.

\section{References}

Abel, T., Nguyen, P.V., Barad, M., Deuel, T., Kandel, E.R., and Bourtchouladze, R. 1997. Genetic demonstration of a role for PKA in the late phase of LTP and in hippocampus-based long-term memory. Cell 88: 615-626.

Abraham, W.C. and Bear, M.F. 1996. Metaplasticity: The plasticity of synaptic plasticity. Trends Neurosci. 19: 126-130.

Abraham, W.C. and Tate, W.P. 1997. Metaplasticity: A new vista across the field of synaptic plasticity. Prog. Neurobiol. 52: 303-323.

Arancio, O., Kiebler, M., Lee, C., Lev-Ram, V., Tsien, R., Kandel, E., and Hawkins, R. 1996. Nitric oxide acts directly in the presynaptic neuron to produce long-term potentiation in cultured hippocampal neurons. Cell 87: 1025-1035.

Behnisch, T. and Reymann, K.G. 1998. Inhibition of apamin-sensitive calcium dependent potassium channels facilitate the induction of long-term potentiation in the CA1 region of rat hippocampus in vitro. Neurosci. Lett. 253: 91-94.

Bildl, W., Strassmaier, T., Thurm, H., Andersen, J., Eble, S., Oliver, D., Knipper, M., Mann, M., Schulte, U., Adelman, J.P., et al. 2004. Protein kinase CK2 is coassembled with small conductance $\mathrm{Ca}^{2+}$-activated $\mathrm{K}^{+}$channels and regulates channel gating. Neuron 43: 847-858.

Blank, T., Nijholt, I., Kye, M.-J., Radulovic, J., and Spiess, J. 2003. Small-conductance, $\mathrm{Ca}^{2+}$-activated $\mathrm{K}^{+}$channel SK3 generates age-related memory and LTP deficits. Nat. Neurosci. 6: 911-912.

Bond, C.T., Herson, P.C., Strassmaier, T., Hammond, R., Stackman, R., Maylie, J., and Adelman, J.P. 2004. Small conductance 
$\mathrm{Ca}^{2+}$-activated $\mathrm{K}^{+}$channel knock-out mice reveal the identity of calcium-dependent afterhyperpolarization currents. J. Neurosci. 24: 5301-5306.

Capron, B., Sindic, C., Godaux, E., and Ris, L. 2006. The characteristics of LTP induced in hippocampal slices are dependent on slice-recovery conditions. Learn. Mem. 13: 271-277.

Christie, B.R. and Abraham, W. 1994. Differential regulation of paired-pulse plasticity following LTP in the dentate gyrus. Neuroreport 5: 385-388.

Collingridge, G.L., Kehl, S.J., and McLennan, H. 1983. Excitatory amino acids in synaptic transmission in the Schaffer collateral-commissural pathway of the rat hippocampus. J. Physiol. 334: 33-46.

Creager, R., Dunwiddie, T., and Lynch, G. 1980. Paired-pulse and frequency facilitation in the region of the in vitro rat hippocampus. J. Physiol. 299: 409-424.

Deschaux, O., Bizot, J.C., and Goyffon, M. 1997. Apamin improves learning in an object recognition task in rats. Neurosci. Lett. 222: 159-162.

Faber, E.S.L., Delaney, A.J., and Sah, P. 2005. SK channels regulate excitatory synaptic transmission and plasticity in the lateral amygdala. Nat. Neurosci. 8: 635-641.

Fanger, C.M., Ghanshani, S., Logsdon, N.J., Rauer, H., Kalman, K., Zhou, J., Beckingham, K., Chandy, K.G., Cahalan, M.D., and Alyar, J. 1999. Calmodulin mediates calcium-dependent activation of the intermediate conductance KCa channel, IKCa1. J. Biol. Chem. 274: $5746-5754$.

Fournier, C., Kourrich, S., Soumireu-Mourat, B., and Mourre, C. 2001. Apamin improves reference memory but not procedural memory in rats by blocking small conductance $\mathrm{Ca}^{2+}$-activated $\mathrm{K}^{+}$channels in an olfactory discrimination task. Behav. Brain Res. 121: 81-93.

Frey, U., Huang, Y.-Y., and Kandel, E.R. 1993. Effect of cAMP stimulate a late stage of LTP in hippocampal CA1 neurons. Science 260: $1661-1664$

Giese, K.P., Fedorov, N.B., Filipkowski, R.K., and Silva, A.J. 1998. Autophosphorylation at Thr286 of the $\alpha$ calcium-calmodulin kinase II in LTP and learning. Science 279: 870-873.

$\mathrm{Gu}$, N., Vervaeke, K., Hu, H., and Storm, J.F. 2005. Kv7/KCNQ/M and $\mathrm{HCN} / \mathrm{h}$, but not $\mathrm{K}_{\mathrm{Ca}} 2 / \mathrm{SK}$ channels contribute to the somatic medium after-hyperpolarization and excitability control in CA1 hippocampal pyramidal cells. J. Physiol. 566: 689-715.

Haley, J., Wilcox, G., and Chapman, P. 1992. The role of nitric oxide in hippocampal long-term potentiation. Neuron 8: 211-216.

Huang, Y.-Y. and Kandel, E.R. 1994. Recruitment of long-lasting and protein kinase A dependent long-term potentiation in Ca1 region of hippocampus requires repeated tetanization. Learn. Mem. 1: 74-81.

Huang, Y.Y., Colino, A., Selig, D.K., and Malenka, R.C. 1992. The influence of prior activity on the induction of long-term potentiation. Science 255: 730-733.

Joiner, W.J., Wang, L.-Y., Tang, M.D., and Kaczmarek, L.K. 1997. hSK4, a member of a novel subfamily of calcium-activated potassium channels. Proc. Natl. Acad. Sci. 94: 11013-11018.

Kandel, E.R. 2001. The molecular biology of memory storage: A dialogue between genes and synapses. Science 294: 1030-1038.

Keen, J.E., Khawaled, R., Farrens, D.L., Neelands, T., Rivard, A., Bond, C.T., Janowsky, A., Fakler, B., Adelman, J.P., and Maylie, J. 1999. Domains responsible for constitutive and $\mathrm{Ca}^{2+}$-dependent interactions between calmodulin and small conductance $\mathrm{Ca}^{2+}$-activated potassium channels. J. Neurosci. 19: 8830-8838.

Kelleher III, R.J., Govindarajan, A., Jun, H.Y., Kang, H., and Tonegawa, S. 2004. Translation control by MAPK signaling in long term synaptic plasticity and memory. Cell 116: 467-479.

Kirov, S.A., Sorra, K.E., and Harris, K.M. 1999. Slices have more synapses than perfusion-fixed hippocampus from both young and mature rats. J. Neurosci. 19: 2876-2886.

Köhler, M., Hirschberg, B., Bond, C.T., Kinzie, J.M., Marrion, N.V., Maylie, J., and Adelman, J.P. 1996. Small-conductance, calcium-activated potassium channels from mammalian brain. Science 273: 1709-1714.

Kramár, E.A., Lin, B., Lin, C.-Y., Arai, A.C., Gall, C.M., and Lynch, G. 2004. A novel mechanism for the facilitation of theta-induced long-term potentiation by brain-derived neurotrophic factor. $J$. Neurosci. 24: 5151-5161.

Ko, G.Y. and Kelly, P.T. 1999. Nitric oxide acts as a postsynaptic signaling molecule in calcium/calmodulin-induced synaptic potentiation in hippocampal CA1 pyramidal neurons. J. Neurosci. 19: 6784-6794.

Lynch, G., Larson, J., Kelso, S., Barrionuevo, G., and Schottler, F. 1983. Intracellular injections of EGTA block induction of hippocampal long-term potentiation. Nature 305: 719-721.

Manabe, T., Wyllie, D.J.A., Perkel, D.J., and Nicoll, R.A. 1993.
Modulation of synaptic transmission and long-term potentiation: Effect on paired-pulse facilitation and EPSC variance in the CA1 region of the hippocampus. J. Neurophysiol. 70: 1451-1459.

McNaughton, B.L. 1982. Long-term synaptic enhancement and short-term potentiation in rat fascia dentata act through different mechanisms. J. Physiol. 324: 249-262.

Messier, C., Mourre, C., Bontempi, B., Sif, J., Lazdunski, M., and Destrade, C. 1991. Effect of apamin, a toxin that inhibits $\mathrm{Ca}^{2+}$-dependent $\mathrm{K}$ channels, on learning and memory processes. Brain Res. 551: 322-326.

Mulkey, R.M., Endo, S., Shenolikar, S., and Malenka, R.C. 1994. Involvement of a calmodulin/inhibitor-1 phosphatase cascade in hippocampal long-term depression. Nature 369: 486-488.

Muller, D. and Lynch, G. 1989. Evidence that changes in presynaptic calcium currents are not responsible for long-term potentiation in hippocampus. Brain Res. 479: 290-299.

Ngo-Anh, T.J., Bloodgood, B.L., Lin, M., Sabatini, B.L., Maylie, J., and Adelman, J.P. 2005. SK channels and NMDA receptors form a $\mathrm{Ca}^{2+}$-mediated feedback loop in dendritic spines. Nat. Neurosci. 8: $642-649$.

Nguyen, P.V. and Kandel, E.R. 1997. Brief theta-burst stimulation induces a transcription-dependent late phase of LTP requiring cAMP in area CA1 of the mouse hippocampus. Learn. Mem. 4: 230-243.

Nguyen, P.V., Abel, T., and Kandel, E.R. 1994. Requirement of a critical period of transcription for induction of late phase of LTP. Science 265: 1104-1107.

Obermair, G.J., Kaufmann, W.A., Knaus, H.-G., and Flucher, B.E. 2003. The small conductance $\mathrm{Ca}^{++}$-activated $\mathrm{K}^{+}$channel SK3 is localized in nerve terminals of excitatory synapses of cultured mouse hippocampal neurons. Eur. J. Neurosci. 17: 721-731.

O'Dell, T.J. and Kandel, E.R. 1994. Low-frequency stimulation erases LTP through an NMDA receptor-mediated activation of protein phosphatases. Learn. Mem. 1: 129-139.

O'Dell, T.J., Hawkins, R.D., Kandel, E.R., and Arancio, O. 1991. Tests of the roles of two diffusible substances in long-term potentiation: Evidence for nitric oxide as a possible early retrograde messenger. Proc. Natl. Acad. Sci. 88: 11285-11289.

Sah, P. 1996. $\mathrm{Ca}^{2+}$-activated $\mathrm{K}^{+}$currents in neurons: Types, physiological roles and modulation. Trends Neurosci. 4: 150-154.

Schulz, P.E., Cook, E.P., and Johnston, D. 1994. Changes in paired-pulse facilitation suggest presynaptic involvement in long-term potentiation. J. Neurosci. 14: 5325-5337.

Schuman, E. and Madison, D. 1994. Locally distributed synaptic potentiation in the hippocampus. Science 263: 532-536.

Scuvée-Moreau, J., Liégeois, J.-F., Massotte, L., and Seutin, V. 2002. Methyl-laudanosine: A new pharmacological tool to investigate the function of small-conductance $\mathrm{Ca}^{2+}$-activated $\mathrm{K}^{+}$channels. $J$. Pharmacol. Exp. Ther. 302: 1176-1183.

Stackman, R.W., Hammond, R.S., Linardatos, E., Gerlach, A., Maylie, J. Adelman, J.P., and Tzounopoulos, T. 2002. Small conductance $\mathrm{Ca}^{2+}$-activated $\mathrm{K}^{+}$channels modulate synaptic plasticity and memory encoding. J. Neurosci. 22: 10163-10171.

Stocker, M. and Pedarzani, P. 2000. Differential distribution of three $\mathrm{Ca}^{2+}$-activated $\mathrm{K}^{+}$channel subunits, SK1, SK2, and SK3, in the adult rat central nervous system. Mol. Cell. Neurosci. 15: 476-493.

Stocker, M., Krause, M., and Pedarzani, P. 1999. An apamin-sensitive $\mathrm{Ca}^{2+}$-activated $\mathrm{K}^{+}$current in hippocampal pyramidal neurons. Proc. Natl. Acad. Sci. 96: 4662-4667.

Wang, J.-H. and Kelly, P.T. 1996. Regulation of synaptic facilitation by postsynaptic $\mathrm{Ca}^{2+} / \mathrm{CaM}$ pathways in hippocampal CA1 neurons. J. Neurophysiol. 76: 276-286.

Williams, J.H., Li, Y.-G., Nayak, A., Errington, M.L., Murphy, K.P.S.J., and Bliss, T.V.P. 1993. The suppression of long-term potentiation in rat hippocampus by inhibitors of nitric oxide synthase is temperature and age dependent. Neuron 11: 877-884.

Woo, N.H. and Nguyen, P.V. 2002. "Silent" metaplasticity of the late phase of long-term potentiation requires protein phosphatases. Learn. Mem. 9: 202-213.

Xia, X.-M., Fakler, B., Rivard, A., Wayman, G., Johnson-Pais, T., Keen, J.E., Ishii, T., Hirschberg, B., Bond, C.T., Lutsenko, S., et al. 1998. Mechanism of calcium gating in small-conductance calcium-activated potassium channels. Nature 395: 503-507.

Zhang, L., Kirschstein, T., Sommersberg, B., Merkens, M., Manahan-Vaughan, D., Elgersma, Y., and Beck, H. 2005. Hippocampal synaptic metaplasticity requires inhibitory autophosphorylation of $\mathrm{Ca}^{2+} /$ calmodulin-dependent kinase II. $J$. Neurosci. 25: 7697-7707.

Received March 9, 2007; accepted in revised form April 3, 2007. 


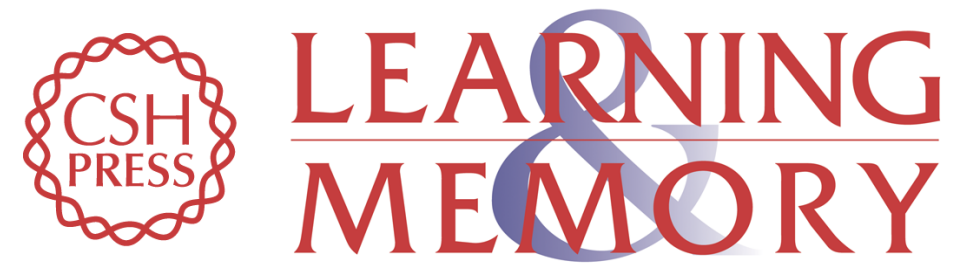

\section{Metaplastic effect of apamin on LTP and paired-pulse facilitation}

Laurence Ris, Brigitte Capron, Coralie Sclavons, et al.

Learn. Mem. 2007, 14:

Access the most recent version at doi:10.1101//m.571007

References This article cites 54 articles, 25 of which can be accessed free at: http://learnmem.cshlp.org/content/14/6/390.full.html\#ref-list-1

License

Email Alerting Receive free email alerts when new articles cite this article - sign up in the box at the Service top right corner of the article or click here. 